\title{
SPASTIC CEREBRAL PALSY AT AGE 5 HAS BETTER FUNCTIONAL OUTCOME IN EXTREME PREMATURITY THAN IN TERM CHILDREN
}

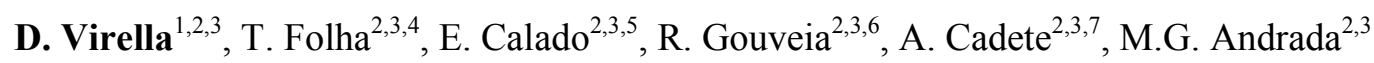

${ }^{I}$ Neonatal Intensive Care Unit, Hospital de Dona Estefânia, Centro Hospitalar de Lisboa Central, ${ }^{2}$ National Surveillance of Cerebral Palsy in Portugal among 5-years-old Children, Federação das Associações Portuguesas de Paralisia Cerebral, Lisboa, Portugal, ${ }^{3}$ Surveillance of Cerebral Palsy in Europe, Grenoble, France, ${ }^{4}$ Centro de Reabilitação de Paralisia Cerebral Calouste Gulbenkian, Santa Casa da Misericórdia de Lisboa, ${ }^{5}$ Paediatric Neurology, Hospital de Dona Estefânia, Centro Hospitalar de Lisboa Central,

${ }^{6}$ Sociedade Portuguesa de Pediatria do Neurodesenvolvimento, Sociedade Portuguesa de Pediatria (SPP), Lisboa, ${ }^{7}$ Physical Therapy, Hospital Fernando Fonseca, Amadora, Portugal

Background and aim: Cerebral palsy (CP) is a group of permanent, but not unchanging, disorders of movement and/or posture and of motor function, which are due to a non-progressive interference, lesion, or abnormality of the developing/immature brain (SCPE). Spastic CP is the most common clinical type and the disorders of the development of the premature brain are the most frequent cause. Do the functional outcomes in 5-years-old children with spastic CP differ depending on their gestational age?

Methods: Data from 5-years-old children born in 2001 were analysed (National Surveillance of Cerebral Palsy in Portugal). SCPE definitions and functional classifications (GMFCS, BMFM, IQ, vision, hearing) were used, as well as the Portuguese scales for assessment of communication (as producer), feeding ability and drooling control. Spastic CP cases were selected. Children born with gestational age $\leq 28$ weeks were compared with those born at term ( $\geq 37$ weeks) using non-parametric statistical tests.

Results: From 171 spastic cases among 209 CP children, 117 were included: 88 born at term and 29 born $\leq$ 28 weeks. Spastic CP was bilateral in $70 \%$ of the term children and $90 \%$ of those born $\leq 28$ weeks. Including every type of spastic CP, those born $\leq 28$ weeks scored significantly better for communication and drooling control only. Comparing only children with bilateral spastic CP, those born $\leq 28$ weeks scored significantly better in every item but vision and hearing.

Conclusion: Bilateral spastic CP children born $\leq 28$ weeks have significantly better function than their counterparts born at term. 